\title{
ECT of Major Depressed Patients in Relation to Biological and Clinical Variables: A Brief Overview
}

\author{
Björn Wahlund*,' and Dietrich von Rosen' \\ 'Department of Agricultural Sciences, Biomathematics and Informatics, Sweden
}

\begin{abstract}
The knowledge that spontaneous or induced convulsions can improve mental disorders has been present for several centuries. electroconvulsive therapy (ECT) has undergone fundamental changes since its introduction, and in the last 15-20 years there has been a legitimate renewal of interest for this therapy. Today the indications for use of ECT seem well codified, and its technique and practices have evolved considerably. It is now firmly established as an important and effective method of treating certain severe forms of depression. However, still very little is known about the mechanism of ECT. In this paper, first, we will give a short overview as to how far we have got concerning ECT in relation to various clinical and biological variables. Second, we will describe ECT in relation to electroencephalographic (EEG) technique and clinical outcome as well as give some proposals as to how to go on with the data analysis of EEG. In conclusion, the superior effect of ECT compared to other antidepressives in severe depression may depend on neurochemical and neurobiological cascade effects initiated by repeated treatments. Above all, ECT offers a unique experimental opportunity to study how neuromodulation of the major transmitter systems may be involved in brain dynamics and alteration of connectivity.

Neuropsychopharmacology (2003) 28, S2I-S26. doi: I 0. I038/sj.npp. I 300135
\end{abstract}

Keywords: ECT; EEG; depression; mechanism; connectivity; review

\section{INTRODUCTION}

For over 50 years clinicians have administered electroconvulsive therapy (ECT). Although, a lot of information from animal and human studies has been aggregated, still there are more questions than there are answers.

\section{ECT IN RELATION TO VARIOUS BIOLOGICAL VARIABLES}

A summary of effects on biological variables of ECT presented below can also be seen in Table 1 .

1. Neurotrophic factors - cell growth and neuroplasticity,

2. hormones and neuropeptides,

3. brain neurotransmitters and their receptors, and

4. imaging techniques.

\section{Neurotrophic Factors - Cell Growth and Neuroplasticity}

The growth factors are a heterogeneous group of polypeptides able to regulate different functions as growth and differentiation, and the trophism of specialized cell phenotypes.

\footnotetext{
*Correspondence: Dr B Wahlund, Department of Clinical Neuroscience, Karolinska Institute, Section of Psychiatry, St. Göran's Hospital, S- I I28 I Stockholm, Sweden. Tel: +46 8 6886605, Fax +46 8 6876806, E-mail: bwah@telia.com

Received OI September 2002; revised 03 November 2002; accepted 03 December 2002
}

Several of these neurotrophic factors (brain-derived neurotrophic factor, nerve growth factor as well as some neuropeptides) seem, in animal studies, to increase their protein synthesis in nerve cells in CNS by both electroconvulsive shock (ECS) and antidepressant medication (Gall et al, 1991).

Stress is important in the etiology of affective disorders. An extended period of stress gives reduction in BDNF in the hippocampus and cortex. This is counteracted by the ECS.

BDNF increases the formation of new serotonergic synapses, and the metabolism of serotonin and noradrenaline (Bergsholm, 1999).

Madsen et al (2000) showed on rats that a single ECS significantly increased the number of newborn nerve cells in the dentate gyrus. These cells survived for at least 3 months. A series of seizures further increased neurogenesis, indicating a dose-dependent mechanism, probably mediated by neurotrophic factors. Generation of new neurons in the hippocampus may be an important neurobiological element underlying the clinical effects of ECSs.

Scott et al (2000) examined the effects of ECS on neurogenesis in the dentate gyrus of the adult rat using bromodeoxyuridine (BrdU) immunohistochemistry, which identifies newly generated cells. At 1 month following eight ECS seizures, ECS-treated rats had approximately twice as many BrdU-positive cells as sham-treated controls. These data suggest that there is a net increase in neurogenesis within the hippocampal dentate gyrus following ECS treatment. Similar increases have been reported following 
Table I Effect of ECT or ECS on Various Biological Variables Under Study and Potential Relations to Clinical Outcome

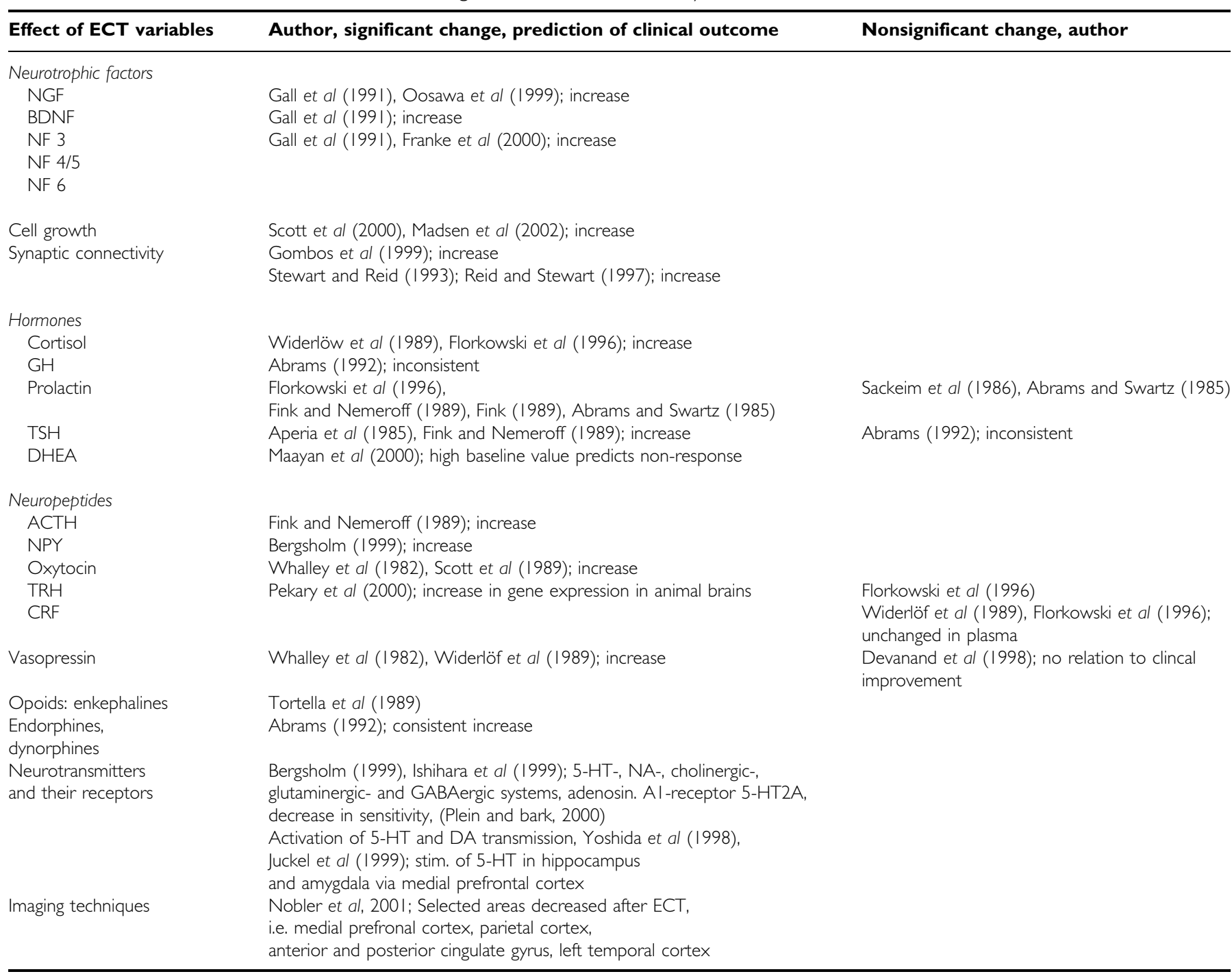

kindling and kainic acid- or pilocarpine-induced status epilepticus. Increased neurogenesis appears to be a general response to seizure activity and may play a role in the therapeutic effects of ECT. Nevertheless, it still remains to test if the newborn neurons have the same function as the lost neurons.

Not only neurogenesis is positively influenced by neurotrophic factors but also neuroplasticity has been found to increase in animal studies in parts of the CNS.

The role of the mossy fibers (axons of nuclear cells of dentate gyrus) is conduction of impulses in the hippocampus. The elicitation of repeated focal seizures (kindling) induces mossy fiber sprouting in the hippocampus of rat. Significant sprouting, but not significant cell loss, was seen in the fascia dentata of the subjects that had received ECS (Gombos et al, 1999).

Repeated electroconvulsive shock (ECS) consistently enhances synaptic connectivity in the dentate gyrus of the rodents. These effects lasted for at least 40 days after the end of the course of ECS, and developed incrementally seizure by seizure during the course of stimulation. The maximum effect was reached only after 4-6 ECS applications (Stewart and Reid, 1993; Reid and Stewart, 1997), interesting in line with the minimum number of ECT given to depressed humans in order to get a good clinical effect.

$\mathrm{N}$-methyl D-aspartate (NMDA) receptor-associated channel-blocker ketamine prevented the change in connectivity, implicating excitatory amino-acid neurotransmission in the action of ECS (Petrie et al, 2000).

Synaptic connectivity might be stimulated not only in the hippocampus but also in other regions of the brain such as in amygdala and frontal and prefrontal areas (LeDoux 1996; Reid and Stewart, 2001). These areas are involved in cognitive and emotional processes and might in some way have altered function in affective disorders.

Thus, much speaks for a cause and time-dependent relation between repeated ECS/ECT (at least in animal studies), causing increased synthesis of neurotrophic factors in turn giving rise to induction of newborn cells in the hippocampus and increased synaptic connectivity forming the basis for clinical improvement. On the other hand, two in vitro studies indicate that neurotrophins do 
not induce newborn cells, rather they promote survival of neurons (Franke et al, 2000; Oosawa et al, 1999).

\section{Hormones and Neuropeptides}

By far the most consistent neurochemical result of ECTinduced seizures is the 10- to 50 -fold increase in serum prolactin levels immediately after ECT and return to baseline within $2 \mathrm{~h}$ (Abrams, 1992).

Basal and ECT-induced cortisol increase after ECT as well as ACTH in humans and fall across a course of ECT (Fink and Nemeroff, 1989; Abrams, 1992; Florkowski et al, 1996). Reports on the release of thyroid-stimulating hormone (TSH) are inconsistent (Abrams, 1992). Like prolactin and cortisol, the amount of TSH reported to be elevated immediately after ECT falls across a course of ECT (Aperia et al, 1985; Scott et al, 1989). Although thyreotropinreleasing hormone is not reported to be released by ECT (Whalley et al, 1982), animal studies have shown that ECS can alter the expression and secretion of TRH-related peptides in the hypothalamus, cingulate, and lateral cerebellum (Pekary et al, 2000).

No change in corticoreleasing factor in blood was found after ECT (Widerlöw et al, 1989; Florkowski et al, 1996) but plasma levels of corticotropin increased (Widerlöw et al, 1989).

Growth hormone (GH) levels are generally reported to be unchanged or reduced immediately after ECT (Abrams, 1992).

Scott et al (1986) and Whalley et al (1987) found that measures of oxytocin release from the posterior pituitary (serum concentrations of oxytocin-associated neurophysin) correlated with clinical measures of improvement in depression but did not correlate with seizure duration. Both plasma levels of oxytocin and arginin vasopressin rise abruptly after ECT but return to baseline after $30 \mathrm{~min}$ (Whalley et al, 1982; Widerlöw et al, 1989). On the other hand, Devanand et al (1998) did not find any relation between clinical improvement and levels of vasopressin or oxytocin. Neuropeptide $\mathrm{Y}$ have been demonstrated to be elevated in the limbic system in rats and the peptide is proposed to play a role in the pathophysiology of depressive disorders (Jiminez-Vasquez et al (2000)).

Plasma dehydroepiandrosterone sulfate levels were markedly elevated in psychotic depressed patients and were associated with resistance to ECT thus serving as a potentially predictive marker of nonresponsiveness to ECT in psychotic depressed patients (Maayan et al, 2000).

ECT increases baseline endorphins consistently (Abrams, 1992).

The immediate increase of cortisol and prolactin after ECT/ECS might be an effect of physiologically induced stress and might be looked upon as epiphenomenom of seizure activity and unlikely provide insights into antidepressant mode of action of ECT. On the other hand, because more prolactin is released by bilateral than unilateral ECT (Abrams, 1992), and by higher dosage electrical stimuli (Robin et al, 1985; Abrams and Swartz, $1985 \mathrm{~b}$ ), the amount of released prolactin may reflect the physiological effects of the ECT technique used.

Interestingly, in intracerebral stimulation using depth electrodes in patients with partial epilepsy, there is evidence for a relation between intracerebral stimulation or seizures and prolactin release. Sperling and Wilson (1986) found that only stimulations producing a high-frequency regional limbic afterdischarge resulted in serum prolactin elevation. Sperling et al (1986) reported that prolactin levels always rose after complex partial seizures involving limbic discharges. The authors concluded that prolactin release resulted from discharges from mesial temporal structures to ventromedial hypothalamus.

Increased oxytocin levels after ECT/ECS and the positive correlation to clinical is interesting in the light of the finding of released oxytocin and its involvement in the mechanism of social bonding and social recognition in laboratory studies. The consistent findings of increased endorphins might reflect dopamine release. Dopamine plays an important role in severe depression and is associated with symptoms like psychomotor retardation.

\section{Brain Neurotransmitters and their Receptors}

ECS in animal studies induces changes in various neurotransmitter systems in the brain. Serotonin (5-hydroxytryptaminergic (5-HT)) is one of the most important neurotransmitters involved in affective disorders. ECT alters serotonergic transmission as well as several subtypes of 5-HT-receptors in CNS (Bergsholm, 1999; Ishihara et al, 1999).

An increase in the number of platelet $5-\mathrm{HT}_{2}$ receptors after ECT was found in 12 major depressed patients (StainMalmgren et al, 1998).

There was a significant drop in the platelet response to serotonin stimulation over a course of ECT. This may suggest decreased sensitivity of platelet $5-\mathrm{HT}_{2 \mathrm{~A}}$ receptors as a mechanism of action of ECT (Plein and Berk, 2000).

Yoshida et al (1998) found an activating effect of repeated ECT on 5-HT and DA neurotransmission (especially on 5HT neurotransmission). McGarvey et al (1993) demonstrated that ECS-induced dopamine release depended on the effects of electrode placements and stimulus intensity. Juckel et al (1999) demonstrated that electrical stimulation on medial prefrontal cortex (PFC) produced currentdependent increases in limbic 5-HT output in both urethane-anesthetized and behaving rats. They concluded that this pronounced regional specificity of the medial PFC stimulation on limbic 5-HT output suggests that activation of this particular area might play a crucial role in such antidepressant treatment as ECT and trans-magnetic stimulation.

ECT decreases plasma noradrenaline in melancholic/ psychotic depressive illness and this shows a trend associated with clinical improvement (Kelly and Cooper, 1997).

Platelet alpha 2-adrenoceptors are supersensitive in depressed patients and treatment with ECT results in the downregulation of these receptors, which may be interpreted as a primary therapeutic, 'normalizing' effect (Werstiuk et al, 1996).

The clinical efficacy of antidepressant medication and ECS may be mediated, in part, through the reduction of Locus Ceruleus (LC) neural activity. The findings reported by Grant and Weiss (2001) are consistent with recent indications that LC-neurons are hyperactive in depressed individuals and with suggestions that some behavioral changes seen in depression can arise from consequences of 
rapidly depolarizing LC-terminals, such as the release of peptides.

ECS also have an effect on the cholinergic and glutaminergic system as well as on GABAergic system (Bergsholm, 1999; Ishihara et al, 1999).

Thus, ECT alters serotoninergic transmission considered as a characteristic of major depression as well as some receptor functions in noradrenergic and dopamnergic neurons decrease, resulting in an increase in the release of noradrenaline, dopamine, and other neurotransmitters (Ishihara et al, 1999).

\section{Imaging Techniques}

Widespread regions of decreased regional cerebral glucose metabolism were identified after ECT, especially in the frontal and parietal cortex, anterior and posterior cingulate gyrus, and left temporal cortex. A region-of-interest analysis similarly indicated post-ECT reductions in regional cerebral glucose metabolism. ECT reduces neuronal activity in selected cortical regions; a potential anticonvulsant and antidepressant effect (Nobler et al, 2001; Yatham et al, 2000). Responders of ECT had reduced regional central blood flow in the frontal regions as compared with nonresponders and controls (Nobler et al, 2000a).

Ende et al (2000) reported that ECT is not likely to induce hippocampal atrophy or cell death, which would be reflected by the decrease in $\mathrm{N}$-acetylaspartate signal, using Proton Magnetic Resonance Spectroscopic Imaging. Compared with an age-matched control group, choline-containing compounds signals in patients with major depressive episodes were significantly lower than normal, before ECT and normalized during ECT.

\section{ECT IN RELATION TO EEG TECHNIQUE AND CLINICAL OUTCOME}

Modern brief pulse ECT devices provide the facility to monitor the seizure by an EEG, electrocardiogram, and muscle activity. EEG technique is a powerful method in collecting 'brain waves' and is useful as a monitoring tool during ECT.

The EEG usually during the muscle seizure develops patterned sequences consisting of high voltage sharp waves and spikes, followed by rhythmic slow waves that end abruptly in a well-defined end point.

The pattern of the EEG during seizure and interseizure after ECT stimulation related with patients who responded greater with clinical improvement might be summarized as follows:

(1) During seizure patients exhibited greater midictal EEG slow-wave amplitude and greater postictal suppression (Nobler et al, 1993), and (2) during interseizure EEG and with increasing number of treatments, EEG showed progressive increase in amplitudes, a slowing and greater rhythmicity of frequencies, and development of burst patterns. Improvement in in-patient behavior (observed as a decrease in psychosis, lifting depressed mood, and decrease in psychomotor agitation) was associated with the development of high degrees of EEG change (Fink and Kahn, 1957). The EEG characteristics predicted which patients had improved or not. The association between
ECT-induced EEG slowing and improvement in depressive symptoms was confirmed by Sackeim et al (1996). ECT produced a short-term increase in delta and theta power in the PFC associated with clinical improvement (Fink and Abrams, 1998).

On the other hand, Nobler et al (2000b) raised doubt about the clinical utility of algorithms, frequently used in ECT equipments in determining the effect of the stimulus dosage, based on the analysis of EEG features to guide ECT parameter selection. Thus, the association between clinical outcome and high power of the ictal EEG was small.

\section{STATISTICAL AND MATHEMATICAL CONSIDERATIONS}

The EEG-output is very complicated to analyze and interpret. The underlying mechanism of generating potentials is complex and one natural class of models does not exist, which covers the dynamics as well as the variation. It is not clear what should be regarded as the deterministic part of the signals, what should be regarded as random variation, and what should be regarded as random error. In those materials we want to analyze we need at least to control for sex and age differences. There is also a natural variation among individuals, which has to be taken into account, which for instance leads us to models with random parameters. Furthermore, because of the ECT treatment the EEG-output must be looked upon as nonstationary. Patients are treated under anesthesia and during treatment a lot of activities are going on, which certainly can influence the EEG-output. This is difficult to completely control for and therefore may be viewed as random noise with a substantial effect on the signals but fortunately usually last for a short time period. To the best of our knowledge we do not know about any paper, which takes all these considerations into account when modeling ECT and EEG.

\section{SUMMARY}

ECT is by far the most effective way to get a severely and /or psychotic depressed patient into remission probably because of the effects on several targets in the CNS system. The findings of restored neuromodulating systems such as serotonergic, adrenergic, and dopaminergic systems as well as release of neurotrophic factors indicates that ECT has effects on the neurochemical transmission and rearrangement of neural net works as well as on cell growth.

Neuromodeling the EEG signals might be a way to test the potential relations between various neuromodulators, neurobiological variables, and clinical state in order to get a better understanding of how the brain works especially studies of how the brain works as an extremely complex system. Unfortunately, results from animal studies have a limited value while neurochemistry and neurophysiology may vary from species to species. Other limitations in many of the referred studies are the relatively small sample making interpretations hazardous.

\section{REFERENCES}

Abrams R (1992). Electroconvulsive Ther. Oxford University Press Inc.: New York. 
Abrams R, Sukartz CM (1985b). ECT and Prolactin release: effects of stimulus parameters. Convuls Ther 1: 115-119.

Aperia B, Thoren M, Wetterberg L (1985). Prolactin and thyrotropin in serum during electroconvulsive therapy in patients with major depressive illness. Acta Psychiatr Scand 72: 302-308.

Bergsholm P (1999). Electroconvulsive therapy. Handout. Depresjenshandbekon. p. 115-144.

Devanand DP, Lisanby S, Lo ES, Fitzsimons L, Cooper TB, Halbreichu, Sackeim HA (1998). Effects of electroconvulsive therapy on plasma visopressin and oxytocin. Biol Psychiatry 44: 610-616.

Ende G, Braus DF, Walter S, Weber-Fahr W, Henn FA (2000). The hippocampus in-patients treated with electroconvulsive therapy: a proton magnetic resonance spectroscopic imaging study. Arch Gen Psychiatry 57: 937-943.

Fink M, Abrams R (1998). EEG monitoring in ECT: a guide to treatment efficacy. Psychiatr Times XV: 1-8.

Fink M, Kahn RL (1957). Relation of EEG delta activity to behavioral response in electroshock: quantitative serial studies. Arch Neurol Psychiatry 78: 516-525.

Fink M, Nemeroff CB (1989). A neuroendocrine view of ECT. Convuls Ther 5: 296-304.

Florkowski CM, Crozier IG, Nightingale S, Evans MJ, Ellis MJ, Joyce P (1996). Plasma cortisol, PRL, ACTH, AVP and corticotrophin releasing hormone responses to direct current cardioversion and electroconvulsive therapy. Clin Endocrinol (Oxf) 44: 163-168.

Franke B, Bayatti N, Engele J (2000). Neurotrophins require distinct extracellular signals to promote the survival of CNS neurons in vitro. Exp Neurol 165: 125-135.

Gall C, Lauterborn J, Bundman M, Murray K, Isackson P (1991). Seizure and the regulation of neurotrophic factor and neuropeptide gene expression in brain. Epilepsy Res Suppl, 4: 225-245. Review.

Gombos Z, Spiller A, Cottrell GA, Racine RJ, McIntyre Burnham W (1999). Mossy fiber sprouting induced by repeated electroconvulsive shock seizures. Brain Res 844: 28-33.

Grant MM, Weiss JM (2001). Effects of chronic antidepressant drug administration and electroconvulsive shock on locus coeruleus electrophysiologic activity. Biol Psychiatry 49: 117-129.

Ishihara K, Sasa M (1999). Mechanism underlying the therapeutic effects of electroconvulsive therapy (ECT) on depression. Jpn J Pharmacol 80: 185-189.

Jiminez-Vasquez PA, Overstreet DH, Mathé AA (2000). Neuropeptide $\mathrm{Y}$ in male and female brains of flinders sensitive line, a rat model of depression. Effects of electroconvulsive stimuli. $J$ Psychiatr Res 34: 405-412.

Juckel G, Mendlin A, Jacobs BL (1999). Electrical stimulation of rat medial prefrontal cortex enhances forebrain serotonin output: implications for electroconvulsive therapy and transcranial magnetic stimulation in depression. Neuropsychopharmacology 21: $391-398$

Kelly CB, Cooper SJ (1997). Plasma noradrenaline response to electroconvulsive therapy in depressive illness. $\mathrm{Br} J$ Psychiatry 171: $182-186$.

LeDoux J (1996). The Emotional Brain. The Mysterious Underpinnings of Emotional Life. Touchstone: New York.

Luber B, Nobler MS, Moeller JR, Katzman GP, Prudic J, Devanand DP (2000). Quantitative EEG during seizures induced by electroconvulsive therapy: relations to treatment modality and clinical features. II. Topographic analyses. J ECT 16: 229-243.

Maayan R, Yagorowski Y, Grupper D, Weiss M, Kaod MA, Weizman A (2000). Basal plasma dehydroepiandrosterone sulfate level: a possible predictor for response to elctroconvulsive therapy in depressed psychotic in-patients. Biol Psychiatry 48: 693-701.
Madsen TM, Treschow A, Bengzon J, Bolwig TG, Lindvall O, Tingstrom A (2000). Increased neurogenesis in a model of electroconvulsive therapy. Biol Psychiatry 47: 1043-1049.

McGarvey KA, Zis AP, Brown EE, Nomikus GG, Fibiger HC (1993). ECS induced dopamine release: effects of electrode placement, anticonvubant treatment, and stimulus intensity. Biol Psychiatry 34: 152-157.

Nobler MS, Luber B, Moeller JR, Katzman GP, Prudic J, Devanand DP (2000b). Quantitative EEG during seizures induced by electroconvulsive therapy: relations to treatment modality and clinical features I. Global analyses. J ECT 16: 211-228.

Nobler MS, Oquendo MA, Kegeles LS, Malone KM, Campbell CC, Sackheim HA (2001). Decreased regional brain metabolism after ECT. Am J Psychiatry 158: 305-308.

Nobler MS, Roose SP, Prohovnik I, Moeller JR, Louie J, Van Heertum RL (2000a). Regional cerebral blood flow in mood disorders, v.: effects of antidepresant medication in late-life depresssion. Am J Geriatr Psychiatry 8: 289-296.

Nobler MS, Sackeim HA, Solomou M, Luber B, Devanand DP, Prudic J (1993). EEG manifestations during ECT: effects of electrode placements and stimulus intensity. Biol Psychiatry 34: 321-330.

Oosawa H, Fuji T, Kawastima K (1999). Nerve growth factor increases the synthesis and release of acetylcholine and the expression of vesicular acetylcholine transporter in primary cultured rat embryonic septal cells. J Neurosci Res 57: 381-387.

Pekary AE, Meyerhoff JL, Sattin (2000). Electroconvulsive seizures modulate levels of thyrotropin releasing hormone and related peptides in rat hypothalamus, cingulate and lateral cerebellum. Brain Res 884: 174-183.

Petrie RX, Reid IC, Stewart CA (2000). The -methyl-D-aspartate receptor, synaptic plasticity, and depressive disorder. A critical review. Pharmacol Ther 87: 11-25; review.

Plein H, Berk M (2000). Changes in the platelet intracellular calcium response to serotonin in-patients with major depression treated with electroconvulsive therapy: state or trait marker status. Int Clin Psychopharmacol 15: 93-98.

Reid IC, Stewart CA (1997). Seizures, memory and synaptic plasticity. Seizure 6: 351-359; review.

Reid IC, Stewart CA (2001). How antidepressants work: new perspectives on the pathophysiology of depressive disorder. $\mathrm{Br} \mathrm{J}$ Psychiatry 178: 299-303; review.

Robin A, Binnie CD, Copas JB (1985). Electrophysiological and hormonal responses to three types of electroconvulsive therapy. Br J Psychiatry 147: 707-712.

Sackeim HA, Luber B, Katzman GP, Moeller JR, Prudic J, Devanand DP (1996). The effects of electroconvulsive therapy on quantitative electroencephalograms. Relationship to clinical outcome. Arch Gen Psychiatry 53: 814-824.

Scott AIF, Milner JB, Shering PA (1989). Diminished TSH release after course of ECT: altered monoamine function or seizure activity? Psychoneuroendocrinology 14: 425-431.

Scott AI, Whalley LJ, Legros JJ (1989). Treatment outcome, seizure duration, and the neurophysin respons to ECT. Biol Psychiatry 25: 585-597.

Scott BW, Wojtowicz JM, Burnham WM (2000). Neurogenesis in the dentate gyrus of the rat following electroconvulsive shock seizures. Exp Neurol 165: 231-236.

Shah PJ, Ebmeier KP, Glabus MF, Goodwin GM (1998). Cortical grey matter reductions associated with treatment-resistant chronic unipolar depression. Controlled magnetic resonance imaging study. Br J Psychiatry 172: 527-532.

Sperling MR, Pritchard PB, Engel Jr J, Daniel C, Sagel J (1986). Prolactin in partial epilepsy: an indicator of limbic seizures. Ann Neurol 20: 716-722.

Sperling MR, Wilson CL (1986). The effects of limbic and extralimbic electrical stimulation upon prolactin secretions in humans. Brain Res 371: 293-297. 
Stain-Malmgren R, Tham A, Aberg-Wistedt A (1998). Increased platelet 5-HT2 receptor binding after electroconvulsive therapy in depression. J ECT 14: 15-24.

Stewart C, Reid I (1993). Electroconvulsive stimulation and synaptic plasticity in the rat. Brain Res 620: 139-141.

Stewart CA, Reid IC (2000). Repeated ECS and fluoxetine administration have equivalent effects on hippocampal synaptic plasticity. Psychopharmacology (Berl) 148: 217-223.

Tortella FC, Long JB, Hong J-S, Holaday JW (1989). Modulation of endogenous opoid system by electroconvulsive shock. Convulsive Ther 5: 261-273.

Uvnas-Moberg K, Bjorkstrand E, Hillegart V, Ahlenius S (1999). Oxytocin as a possible mediator of SSRI-induced antidepressant effects. Psychopharmacology (Berl) 142: 95-101.

Werstiuk ES, Coote M, Griffith L, Shannon H, Steiner M (1996). Effects of electroconvulsive therapy on peripheral adrenoceptors, plasma, noradrenaline, MHPG and cortisol in depressed patients. Br J Psychiatry 169: 758-765.
Whalley LJ, Eagles JM, Bowler GM, Bennie JG, Dick HR, McGuire RJ (1987). Selective effects of ECT on hypothalamic-pituitary activity. Psychol Med 17: 319-328.

Whalley LJ, Rosie R, Dick H, Levy G, Watts AG, Sheward WJ (1982). Immediate increases in plasma prolactin and neurophysin but not other hormones after electroconvulsive therapy. Lancet 2: 1064-1068.

Widerlöw E, Ekman R, Jensen L, Borglund L, Nyman K (1989). Arginine vasopressin, but not corticotropin releasing factor, is a potent stimulator of adrenocorticotropic hormone following electroconvulsive treatment. J Neural Transm 75: 101-109.

Yatham LN, Clark CC, Zis AP (2000). A preliminary study of the effects of electroconvulsive therapy on regional brain glucose metabolism in patients with major depression. J ECT 16: 171-176.

Yoshida K, Higuchi H, Kamata M, Yoshimoto M, Shimizu T, Hishikawa Y (1998). Single and repeated electroconvulsive shocks activate dopaminergic and 5-hydroxytryptaminergic neurotransmission in the frontal cortex of rats. Prog Neuropsychopharmacol Biol Psychiatry 22: 435-444. 